\title{
FINITE ELEMENT ANALYSIS AND MODELING OF TEMPERATURE DISTRIBUTION IN TURNING OF TITANIUM ALLOYS
}

\author{
M. M. Reddy*, B. M. Kumar, S. Kumaraesan \\ School of Engineering \& Science, Curtin University Sarawak, CDT 250 Miri, \\ Sarawak 98009, Malaysia
}

Received 28.09.2018

Accepted 25.03.2018

\begin{abstract}
The titanium alloys (Ti-6Al-4V) have been widely used in aerospace, and medical applications and the demand is ever-growing due to its outstanding properties. In this paper, the finite element modeling on machinability of Ti-6Al-4V using cubic boron nitride and polycrystalline diamond tool in dry turning environment was investigated. This research was carried out to generate mathematical models at $95 \%$ confidence level for cutting force and temperature distribution regarding cutting speed, feed rate and depth of cut. The Box-Behnken design of experiment was used as Response Surface Model to generate combinations of cutting variables for modeling. Then, finite element simulation was performed using AdvantEdge ${ }^{\circledR}$. The influence of each cutting parameters on the cutting responses was investigated using Analysis of Variance. The analysis shows that depth of cut is the most influential parameter on resultant cutting force whereas feed rate is the most influential parameter on cutting temperature. Also, the effect of the cutting-edge radius was investigated for both tools. This research would help to maximize the tool life and to improve surface finish.
\end{abstract}

Keywords: Titanium Alloy; Finite Element Analysis; Turning; Cutting force; Temperature distribution; Box-Behnken Design.

\section{Introduction}

Titanium and its alloys are widely used in aerospace and aircraft applications since 1950. In the recent years, research has shown that titanium had been dominating other high-performance materials such as aluminum, steel and even composite material due to its outstanding properties in the manufacturing of aircraft engines [1]. The use of titanium and its alloys allow longer operational life and efficient fuel consumption [2]. The high strength-to-weight ratio of titanium property attracts the attention in the aerospace industry. Besides, titanium also possesses excellent creep and rupture

\footnotetext{
*Corresponding author: Moola Mohan Reddy,m.mohan@curtin.edu.my
} 
strength, excellent resistance to the high thermal environment as well as ability to maintain hardness at elevated temperature. The authentic properties of titanium and its alloys increases demand in biomedical applications. The properties such as biocompatibility and high corrosion resistance of titanium are essential to produce implants for various purposes.

However, the low thermal conductivity and high chemical reactivity of titanium is a significant drawback in machining of titanium since it limits the machining rate and the amount of material to be removed [3]. Therefore, the cutting tool and its workpiece play a vital role in titanium machining. The current trend in industries are sighted towards using advanced tool materials such as polycrystalline diamond (PCD), cubic boron nitride $(\mathrm{CBN})$ and binderless cubic boron nitride (BCBN) which exhibit excellent mechanical properties such as high hardness, high wear withstanding property and high thermal stability [4]. In this research, 2D finite element modeling was done to study the temperature distribution and cutting forces. The exact algorithms in AdvantEdge ${ }^{\circledR}$ increases the computational efficiency and adaptive re-meshing feature improves the chip formation morphology.

Earlier studies have shown that CBN and Polycrystalline diamond PCD tools are typically used for machining of titanium at high cutting speed due to their excellent wear resistance $[2,5]$.

Cutting speed, depth of cut and feed rate are the essential parameters that affect the machinability of titanium alloy. Earlier studies show that increase in cutting speed increases the temperature at the tool-chip interface due to the low thermal conductivity of the titanium [6]. Filho et al. [7] reviewed that the high thermal stress on the contact area induces thermal softening which in return lowers the cutting force requirement. However, Oosthuizen et al. [8] stated that it could lead to phenomena such as adhesion (galling) and diffusion wear due to the high chemical affinity of titanium. Moreover, similar findings by Veiga et al. [9], Oosthuizen et al. [8] and Filho et al. [7] have concluded that depth of cut had a significant impact on increasing cutting force generation during the turning process.

Qian and Hossan [10] reported that the increase in feed rate increases the cutting force and feed force. Calamaz [11] stated that the cutting force and temperature increase with an increase in feed rate due to higher shear stress formation. As for tool edge radius, Ozel and Ulutan [12] determined that thrust and feed force increases with increase in tool edge radius with uncoated and coated Tungsten Carbide-Cobalt (WCCo) tool insert. Similarly, Li and Albert [13] reported similar findings and added that peak tool temperature decreases with increase in tool edge radius. Literature review shows that the machining of titanium alloy with $\mathrm{CBN}$ and PCD tools have been limited in turning process.

Machining titanium alloys with dry cutting are difficult. Using advanced tools Like CBN and PCD may improve machinability. This study focuses on how machining performance correlates with advanced tools in dry cutting. This research aims to generate multiple regression models at $95 \%$ confidence level that adequately describes the cutting force and temperature distribution in turning of Ti-6Al-4V. The Finite element analysis was performed, and the numerical results are validated. Analysis of variance was performed using Minitab to study the interaction between cutting parameters on force and temperature responses. Lastly, the impact of tool edge radius on force and temperature responses was analyzed. 


\section{Materials and methods}

The AdvantEdge ${ }^{\circledR}$ simulates the turning process which enables estimation of cutting force and temperature distribution at the tool-chip interface; this allows investigation on the influence of cutting speed, feed rate, depth of cut and tool edge radius on improving tool performance.

\section{Workpiece and Tool Material}

The Chemical composition and physical properties of Ti-6Al-4V are shown in Table 1 and Table 2 respectively. The CBN and PCD cutting tools have configured with a rake angle of $6^{\circ}$, the relief angle of $6^{\circ}$, rake length of $2.0 \mathrm{~mm}$ and relief length of 2.0 $\mathrm{mm}$.

Table 1. Chemical compositions of Ti-6Al-4V.

\begin{tabular}{lccccc}
\hline Elements & $\mathrm{Ti}$ & $\mathrm{Al}$ & $\mathrm{V}$ & $\mathrm{C}$ & $\mathrm{Fe}$ \\
\hline Composition $(\%)$ & Balanced & 5.750 & 4.330 & 0.044 & 0.200
\end{tabular}

Table 2. Physical properties of Ti-6Al-4V.

\begin{tabular}{lcccc}
\hline $\begin{array}{l}\text { Physical } \\
\text { properties }\end{array}$ & $\begin{array}{c}\text { Yield } \\
\text { strength }\end{array}$ & $\begin{array}{c}\text { Elastic } \\
\text { modulus }\end{array}$ & Density & $\begin{array}{c}\text { Thermal } \\
\text { conductivity }\end{array}$ \\
\hline Values & $1050 \mathrm{MPa}$ & $114 \mathrm{GPa}$ & $\begin{array}{c}4430 \\
\mathrm{~kg} / \mathrm{m} 3\end{array}$ & $6.7 \mathrm{~W} / \mathrm{m} . \mathrm{K}$ \\
\hline
\end{tabular}

Design of Experiment

The combination of cutting parameters was chosen using Box Behnken Design (BBD). The BBD uses three level factors (high, middle and low) and total 15 combinations of simulations were performed for each tool. BBD considers final design point and fewer combinations of experiments than Central composite design. The three levels of independent variables, a combination of runs and simulation results are shown in Table 3, Table 4 and Table 5.

Table 3. List of process parameters and their respective level of the factor.

\begin{tabular}{llllll}
\hline \multirow{2}{*}{ Cutting parameter } & \multirow{2}{*}{ Notation } & \multirow{2}{*}{ Units } & \multicolumn{3}{c}{ Level of factor } \\
\cline { 4 - 6 } & & & -1 & 0 & 1 \\
\hline Cutting speed & $\mathrm{v}$ & $(\mathrm{m} / \mathrm{min})$ & 125 & 175 & 225 \\
Feed rate & $\mathrm{f}$ & $(\mathrm{mm} / \mathrm{rev})$ & 0.05 & 0.10 & 0.15 \\
Depth of cut & $\mathrm{d}$ & $(\mathrm{mm})$ & 0.25 & 0.50 & 1.00 \\
\hline
\end{tabular}

\section{Simulation Set-Up}

The maximum tool element size for tool edge radius of $25 \mu \mathrm{m}, 50 \mu \mathrm{m}$, and $75 \mu \mathrm{m}$ are $0.01 \mathrm{~mm}, 0.02 \mathrm{~mm}$ and $0.03 \mathrm{~mm}$ are based on Ducobu et al. [14]. The minimum tool element size is determined from mesh convergence study tested at $v=175 \mathrm{~m} / \mathrm{min}$, $\mathrm{f}=0.10 \mathrm{~mm} / \mathrm{rev}$ and $\mathrm{d}=0.50 \mathrm{~mm}$. From the mesh convergence test, the minimum mesh size of 0.00375 is selected for the turning model. Mesh refinement factor of 5 (medium), and mesh coarsening factor of 8 (coarse) were chosen for the numerical simulation. The study on tool edge radius of both $\mathrm{CBN}$ and PCD tools are performed at $\mathrm{v}=150 \mathrm{~m} / \mathrm{min}, \mathrm{f}=0.15 \mathrm{~mm} / \mathrm{rev}$ and $\mathrm{d}=0.50 \mathrm{~mm}$. A total of three sets of runs were performed for each tool with three different the tool edge radius. 
Table 4. Values of cutting force and temperature obtained through finite element analysis for CBN tool.

\begin{tabular}{cccccc}
\hline Run & $\begin{array}{c}\text { Cutting } \\
\text { speed, } \\
(\mathrm{m} / \mathrm{min})\end{array}$ & $\begin{array}{c}\text { Feed rate, } \\
(\mathrm{mm} / \mathrm{rev})\end{array}$ & $\begin{array}{c}\text { The depth } \\
\text { of cut, } \\
(\mathrm{mm})\end{array}$ & $\begin{array}{c}\text { Resultant } \\
\text { force, } \\
(\mathrm{N})\end{array}$ & $\begin{array}{c}\text { Peak tool } \\
\text { temperature } \\
\left({ }^{\circ} \mathrm{C}\right)\end{array}$ \\
\hline 1 & 125 & 0.15 & 0.50 & 204.27 & 836.54 \\
2 & 175 & 0.05 & 1.00 & 178.83 & 695.19 \\
3 & 175 & 0.15 & 0.25 & 101.91 & 995.93 \\
4 & 125 & 0.10 & 1.00 & 291.92 & 775.06 \\
5 & 125 & 0.05 & 0.50 & 86.24 & 596.28 \\
6 & 175 & 0.10 & 0.50 & 143.55 & 885.68 \\
7 & 125 & 0.10 & 0.25 & 72.98 & 775.06 \\
8 & 225 & 0.05 & 0.50 & 86.73 & 754.23 \\
9 & 225 & 0.10 & 0.25 & 75.65 & 951.07 \\
10 & 175 & 0.05 & 0.25 & 44.71 & 695.19 \\
11 & 175 & 0.15 & 1.00 & 407.65 & 995.93 \\
12 & 225 & 0.15 & 0.50 & 202.63 & 1072.67 \\
13 & 225 & 0.10 & 1.00 & 302.58 & 951.07 \\
14 & 175 & 0.10 & 0.50 & 143.55 & 885.68 \\
15 & 175 & 0.10 & 0.50 & 143.55 & 885.68 \\
\hline
\end{tabular}

Table 5. Values of cutting force and temperature obtained through finite element analysis for PCD tool.

\begin{tabular}{cccccc}
\hline Run & $\begin{array}{c}\text { Cutting } \\
\text { speed, } \\
(\mathrm{m} / \mathrm{min})\end{array}$ & $\begin{array}{c}\text { Feed rate, } \\
(\mathrm{mm} / \mathrm{rev})\end{array}$ & $\begin{array}{c}\text { Depth of } \\
\text { cut, } \\
(\mathrm{mm})\end{array}$ & $\begin{array}{c}\text { Resultant } \\
\text { force, } \\
(\mathrm{N})\end{array}$ & $\begin{array}{c}\text { Tool } \\
\text { temperature, } \\
\left({ }^{\circ} \mathrm{C}\right)\end{array}$ \\
\hline 1 & 125 & 0.15 & 0.50 & 203.18 & 346.30 \\
2 & 175 & 0.05 & 1.00 & 181.30 & 275.05 \\
3 & 175 & 0.15 & 0.25 & 102.45 & 417.73 \\
4 & 125 & 0.10 & 1.00 & 284.56 & 297.98 \\
5 & 125 & 0.05 & 0.50 & 91.50 & 234.24 \\
6 & 175 & 0.10 & 0.50 & 143.26 & 347.38 \\
7 & 125 & 0.10 & 0.25 & 71.14 & 297.98 \\
8 & 225 & 0.05 & 0.50 & 88.91 & 306.35 \\
9 & 225 & 0.10 & 0.25 & 77.85 & 405.22 \\
10 & 175 & 0.05 & 0.25 & 45.32 & 275.05 \\
11 & 175 & 0.15 & 1.00 & 409.79 & 417.73 \\
12 & 225 & 0.15 & 0.50 & 207.43 & 454.08 \\
13 & 225 & 0.10 & 1.00 & 311.40 & 405.22 \\
14 & 175 & 0.10 & 0.50 & 143.26 & 347.38 \\
15 & 175 & 0.10 & 0.50 & 143.26 & 347.38 \\
\hline
\end{tabular}




\section{Result and Discussion}

Mathematical Model

The numerical results obtained from FEA simulation was used to formulate the second order multiple linear regression models for both resultant force and tool edge temperature. The ability of the regression equation to adequately describe the response was evaluated based on significance test performed using Analysis of Variance (ANOVA) at $95 \%$ confidence level. The second order linear multiple regression model for the resultant force and cutting temperature with $\mathrm{CBN}$ tool gives a very high coefficient of correlation (R2) of $99.93 \%$ and $99.80 \%$ respectively.

Also, both regression models are significant as the p-value was less than $5 \%$. Thus, the second order regression model for turning mechanism with CBN and PCD tools predicted from this study were formulated as below:

$$
\begin{aligned}
& F_{C B N}=-9.46+0.0305 v+18.8 f+68.79 d+2277.5 f d \\
& T_{C B N}=-99.1+4.854 v+5087 f+7.82 v f-0.01077 v^{2}-17774 f^{2} \\
& F_{P C D}=13.8-0.0928 v+6.4 f+13.4 d+0.321 v d+2281 f d \\
& T_{P C D}=89.1+0.629 v+1411 f-79.5 d-3362 f^{2}+63.6 d^{2}+3.57 v f
\end{aligned}
$$

Where $v$ is cutting speed $(\mathrm{m} / \mathrm{min}), f$ is feed rate $(\mathrm{mm} / \mathrm{rev}), d$ is the depth of cut $(\mathrm{mm}), F$ is a resultant force $(\mathrm{N})$, and $T$ is cutting temperature.

Study of interactions between cutting speed, feed rate and depth of cut on cutting responses

The influences of cutting parameters on the cutting responses were studied using ANOVA. For turning operation with CBN tools, depth of cut $(71.43 \%)$ is the most influential on cutting force followed by feed rate (23.20\%). A similar conclusion was also drawn from investigations done by Filho et al. [7], Andriya et al. [15] and Singh and Pradeep [16]. As for the cutting temperature analysis, feed rate $(67.49 \%)$ was the most influential factor followed by cutting speed $(27.91 \%)$. These findings show that feed rate and cutting speed are the most influential parameter on temperature response for machining Ti-6Al-4V, and the findings had the best agreement with similar research performed by Kumar et al. [17].

For turning operation with PCD tools, depth of cut (71.69\%) is the most significant on cutting force followed by feed rate $(22.72 \%)$. A similar conclusion was also drawn from investigations done by Andriya et al. [15] and Singh and Pradeep [16]. As for the cutting temperature analysis, feed rate $(64.36 \%)$ is the most influential on cutting temperature followed by cutting speed (33.68\%). These shows that feed rate and cutting speed were the most influential parameter on temperature response for machining Ti-6Al-4V.

For turning with CBN and PCD tool, it was found through interaction plot as depicted in Fig. 1a and Fig. 1c that the resultant cutting force varies slightly with an increase in cutting speed. At lower cutting speed between $125 \mathrm{~m} / \mathrm{min}$ to $175 \mathrm{~m} / \mathrm{min}$, the resultant cutting force decreases with increase in cutting speed. This phenomenon is due 
to thermal softening of the workpiece that reduces the shear stress on the contact interface. However, the tool-workpiece at this cutting speed range is lower compared to the critical temperature of $\mathrm{CBN}$ and $\mathrm{PCD}$ tools of $900{ }^{\circ} \mathrm{C}$ and $760{ }^{\circ} \mathrm{C}$ respectively. Fig. $2 \mathrm{a}$ depicts the workpiece temperature is below $900{ }^{\circ} \mathrm{C}$ during the turning operation using CBN tool. As the tool temperature did not exceed the critical temperature, the tool can maintain its hardness properties. Thus, lowering the cutting force required to unload the chip at low to mid-range of cutting speed.

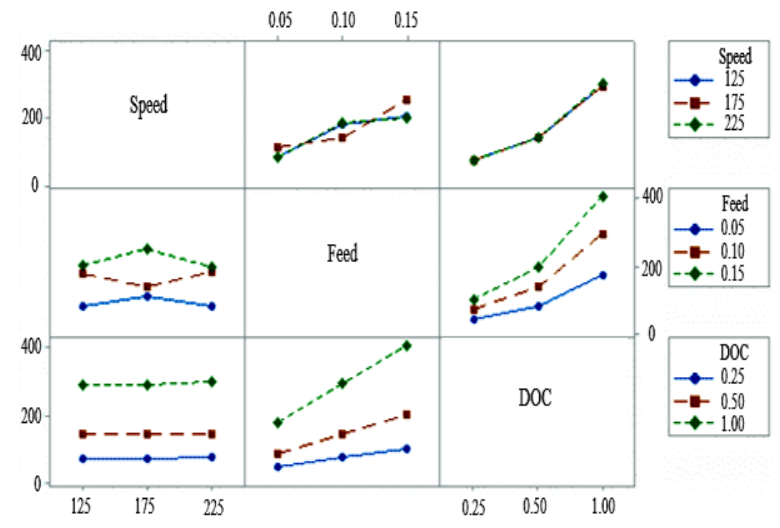

a)

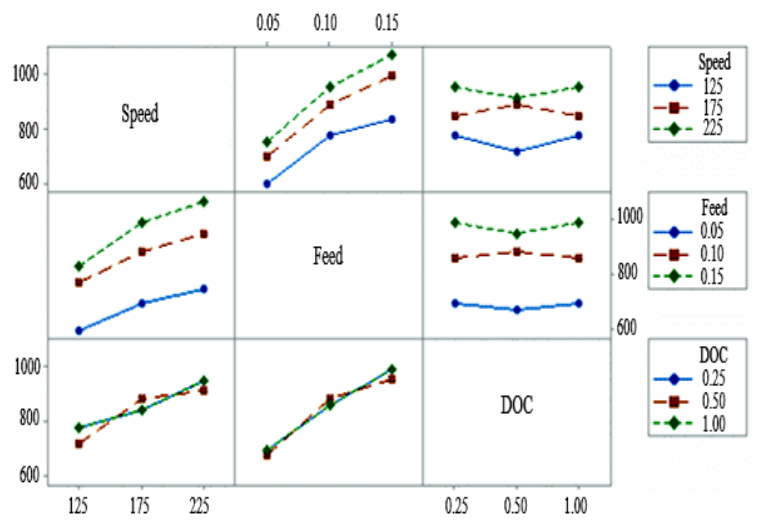

b) 


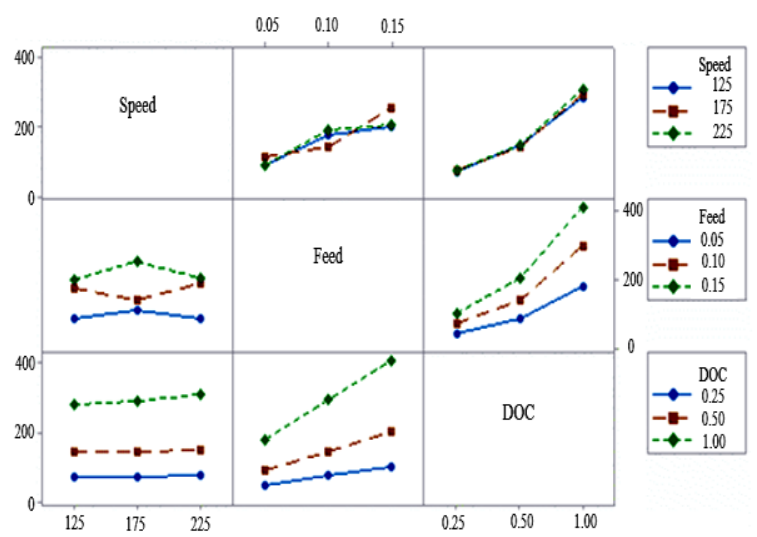

c)

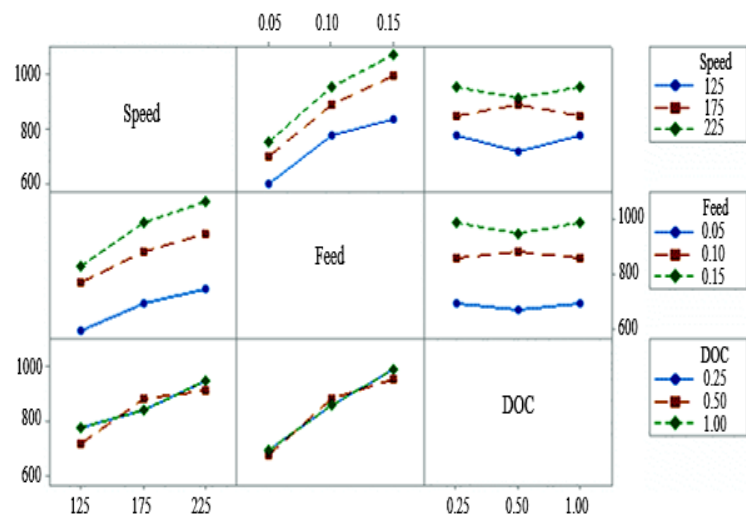

d)

Fig. 1. Interaction plot for a) resultant force under turning with CBN tool, b) temperature under turning with $C B N$ tool c) for the resultant force under turning with PCD tool, $d)$ temperature under turning with PCD tool

However, when the cutting speed increases from $175 \mathrm{~m} / \mathrm{min}$ to $225 \mathrm{~m} / \mathrm{min}-$ resultant cutting force increases. At this condition, the temperature recorded at heat affected zone on the workpiece under CBN and PCD are observed (Fig. 2a) greater than $900{ }^{\circ} \mathrm{C}$ and $840{ }^{\circ} \mathrm{C}$ respectively. This is because Ti-6Al-4V workpiece might have undergone allotropy change to near-beta or beta phase titanium since the temperature was close to transformation temperature of $880{ }^{\circ} \mathrm{C}$. Thus, the force required to remove the workpiece material is increased. Fig. $2 \mathrm{~b}$ shows that the workpiece temperature is above $900{ }^{\circ} \mathrm{C}$ during the turning operation using CBN tool. Yang and Liu [18] report similar findings. In summary, the cutting speed has a little effect on the resultant cutting force. 


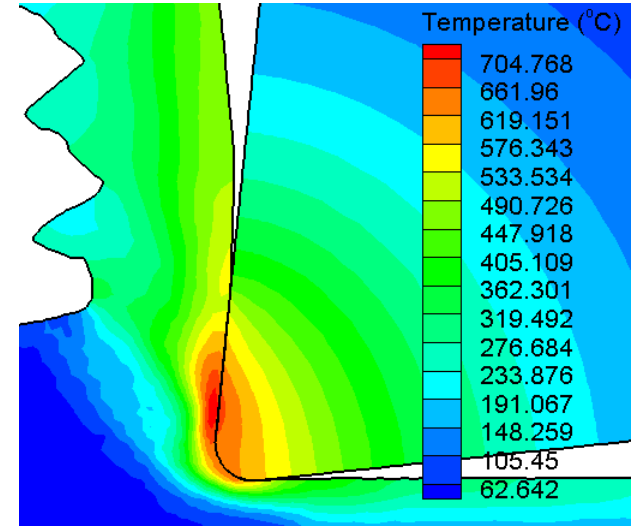

a)

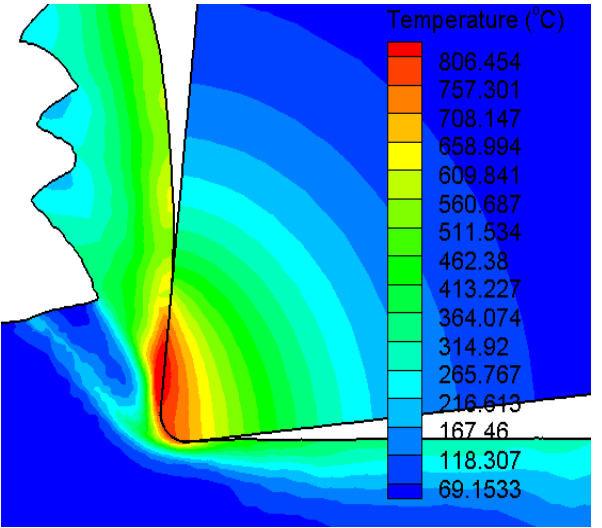

b)

Fig. 2. Temperature distribution contour at the tool-workpiece interface with CBN tool at a) $v=125 \mathrm{~m} / \mathrm{min}$; b) $v=225 \mathrm{~m} / \mathrm{min}$.

From Fig. 1b and Fig. 1d it is observed that the increase in cutting speed results in increases the cutting temperature under both CBN and PCD tools. This is mainly due to titanium has low thermal conductivity and high work hardening. The heat generated at the cutting edge during machining is due to the low thermal conductivity of titanium. Whereas, the work hardening induces a very high bearing load and friction between tool-chip contact interface. Similar findings are reported in the literature $[9,19]$.

As for as feed rate concern, the plots show (Fig. 1) that the resultant force and cutting temperature increase with an increase in the feed rate. The main reason is due to the increase in chip load and induced vibration. Increase in the feed rate produces a higher amount of chip being removed thus generates higher shear stress on the tool which subsequently increases heat formation at the tool cutting edge. Besides, the low elastic modulus of titanium creates vibration from the chattering phenomena upon an increase in feed rate. The chattering effect promotes higher contact friction, thus results in higher resultant cutting force and temperature.

From Fig. 1a and Fig. 1c, it is observed that the cutting force increases with increase in the depth of cut. The reason behind this may be due to chattering effect. The chattering effect resulted from the low elastic modulus of titanium creates higher shearing stress, surface friction, and material removal rate. Thus, increases the cutting force during turning operation. However, the cutting temperature is also found to be mostly unaffected by increasing the depth of cut. Similar findings are reported in the literature $[20,21]$.

The turning of titanium workpiece with $\mathrm{CBN}$ tool is validated with research findings of Veiga et al. [9]. From the validation test, cutting force and temperature show a maximum variation of $5.25 \%$ and $12.06 \%$ respectively. Thus, it shows that simulation results obtained for the machining of Ti-6Al-4V with CBN tool shows a reasonable degree of agreement. All the force plots obtained from the simulation results are subjected to cyclic forces as depicted in Fig. 3. This may be due to the formation of the serrated chip and vibration (chattering). 


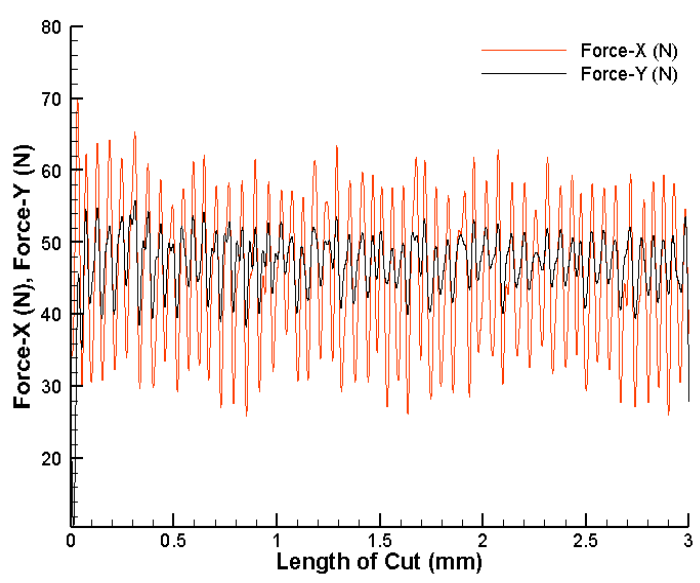

Fig. 3. The cyclic feed force and cutting force at cutting speed of $175 \mathrm{~m} / \mathrm{min}$ and feed rate of $0.05 \mathrm{~mm} / \mathrm{rev}$.

The cutting force and temperature from turning of titanium workpiece with PCD tool are validated with the research findings of Oosthuizen et al. [22] and Pan [23] respectively. From the validation test, the cutting force and temperature show the maximum variation of $22.34 \%$ and $34.86 \%$ respectively. This difference is due to variation in the cutting parameters and the tool property. Therefore, the simulation results obtained for the machining of Ti-6Al-4V with PCD tool shows a good agreement.

\section{Effect of Tool Edge Radius}

From the simulation results (Fig. 2), it is found that there is a significant effect of tool edge radius on cutting force and cutting temperature. This finding shows that, as the cutting tool edge radius is reduced, a very high thermal stress is observed on the cutting tool. The reason behind this phenomenon is due to the contact area and amount of material being removed. Since the cutting-edge radius is small, the tool-chip and the tool-workpiece contact area are small. As the cutting speed is increased, it is observed that significant heat is generated and dissipated to the small contact area due to contact friction and low thermal conductivity of titanium alloy. Thus, increasing the temperature generated during the turning process. However, since the contact area is small, the contact friction and shear stress are much lower compared to the larger tool edge radius is used. Thus, a lower cutting force is required to remove the desired volume of material. These findings are very similar to the results of Veiga et al. [9]. In summary, it is observed that turning off the Ti-6Al-4V workpiece with PCD tool results slightly lower heat generation than the CBN tool.

The accuracy of the simulation results is analyzed by comparing with similar research outcome with various published journal articles. 
Turning of Titanium workpiece with CBN tool

For this test, the simulation results are compared with research findings reported by Veiga et al. [9] and additional simulation is performed at cutting speed of $v=180 \mathrm{~m} / \mathrm{min}, d=0.5 \mathrm{~mm}$ and feed rate $=0.05 \mathrm{~mm} / \mathrm{rev}$. The results are reported in Table 6.

\begin{tabular}{|c|c|c|c|c|c|c|c|}
\hline \multicolumn{3}{|c|}{ Cutting parameter } & \multicolumn{3}{|c|}{ Cutting parameter } & \multirow{3}{*}{\multicolumn{2}{|c|}{$\begin{array}{l}\text { The difference } \\
(\%)\end{array}$}} \\
\hline $\mathrm{f}(\mathrm{mm} / \mathrm{rev})$ & $\mathrm{d}(\mathrm{mm})$ & $\mathrm{v}(\mathrm{m} / \mathrm{min})$ & $\begin{array}{c}\mathrm{f} \\
(\mathrm{mm} / \mathrm{rev})\end{array}$ & $\begin{array}{c}\mathrm{d} \\
(\mathrm{mm})\end{array}$ & $\begin{array}{c}\mathrm{v} \\
(\mathrm{m} / \mathrm{min})\end{array}$ & & \\
\hline \multirow[t]{2}{*}{0.05} & \multirow{2}{*}{\multicolumn{2}{|c|}{ Simulation }} & 0.05 & 0.5 & 185 & & \\
\hline & & & \multicolumn{3}{|c|}{ Experimental (Veiga et al.) } & & \\
\hline $\mathrm{F}(1$ & & $\mathrm{T}\left({ }^{\circ} \mathrm{C}\right)$ & $\mathrm{F}(\mathrm{N}$ & & $\mathrm{T}\left({ }^{\circ} \mathrm{C}\right)$ & $\mathrm{F}(\mathrm{N})$ & $\mathrm{T}\left({ }^{\circ} \mathrm{C}\right)$ \\
\hline 89. & & 689.16 & 85 & & 615 & $5.25 \%$ & $12.06 \%$ \\
\hline
\end{tabular}

From Table 6, it can observe that cutting force and temperature varies by $5.25 \%$ and $12.06 \%$ compared to similar findings from Veiga et al. [9]. The little higher variation observed on temperature value is probably due to the compared value tested at slightly higher cutting speed. Therefore, simulation results obtained for machining of Ti-6Al-4V showed a reasonable degree of agreement.

\section{Conclusions}

In this study, the models are developed for cutting force and temperature distribution in turning of the Ti-6Al-4V workpiece with CBN and PCD tool. From the ANOVA, the study concludes that depth of cut is the most influential parameter on the resultant cutting force. In case of temperature distribution, the feed rate is the most significant parameter.

\section{Acknowledgments}

The authors are grateful to the Ministry of Higher Education (FRGS grant) for support to use software for this work to be possible.

\section{References}

[1] Nageswara Rao Muktinutalapati: Materials for Gas Turbines-An Overview in Advances in Gas Turbine Technology, Ed. Ernesto Benini, 2011, 293-313.

[2] E. O. Ezugwu, J. Bonney, Y. Yamane: J Mater Process. Technol, 134 (2003) 233 253.

[3] S. Schindler, M. Zimmermann, J.C. Aurich, P. Steinmann: Procedia CIRP, 8 (2013): 39-44.

[4] M. W. Cook, P.K. Bossom: Int J Refract Met Hard Mater, 18 (2000) 147-152.

[5] J. R. Davis: ASM Speciality Handbook: Tool Materials, ASM International 1995.

[6] Y. Karpat: J Mater Process Technol, 211 (2011) 737-749.

[7] Ribeiro Filho, Sergio Luiz Moni, Carlos Henrique Lauro, Alysson Helton Santos Bueno, Lincoln Cardoso Brandao: Measurement, 88 (2016) 223-237.

[8] G. A. Oosthuizen, G. Akdogan, D. Dimitrov, N. F. Treurnicht: R \& D Journal of the South African Institution of Mechanical Engineering, 26 (2010) 43-52.

[9] C. Veiga, J. P. Davim, A. J. R. Loureiro: Rev Adv Mater Sci, 34 (2013) 148-164.

[10] Li Qian, Mohammad Robiul Hossan: J Mater Process. Technol, 191 (2007)

274-278. 
M. M. Reddy et al. - Finite Element Analysis and Modeling of Temperature Distribution in ... 69

[11] M. Calamaz, D. Coupard, F. Girot: International Journal of Machine Tools and Manufacture, 48 (2008) 275-288.

[12] T. Ozel, D. Ulutan: CIRP Annals-Manufacturing Technology, 61 (2012) 547-550.

[13] R. Li, A. J. Shih: The International Journal of Advanced Manufacturing Technology, 29 (2006) 253-261.

[14] F. Ducobu, E. Rivière-Lorphèvre, E. Filippi: Simulation Modelling Practice and Theory, 53 (2015) 1-14.

[15] N. Andriya, P. V. Rao, S. Ghosh, In Proceedings of the World Congress on Engineering, London, UK, pp. 4-6. 2012.

[16] H. Singh, P. Kumar: Sadhana, 31 (2006) 671.

[17] R. Kumar, A. Sahoo, K. Satyanarayana, G. Rao: International Journal of Industrial Engineering Computations, 4 (2013) 427-436.

[18] X. Yang, C. Richard Liu: Mach Sci Technol, 3 (1999) 107-139.

[19] A. Pramanik: The International Journal of Advanced Manufacturing Technology, 70 (2014) 919-928.

[20] V. P. Astakhov: The International Journal of Advanced Manufacturing Technology, 34 (2007) 631-640.

[21] S. Debnath, Moola Mohan Reddy, Qua Sok Yi: Measurement, 78 (2016) 111-119.

[22] Oosthuizen, G. Adriaan, G. Akdogan, N. Treurnicht: The International Journal of Advanced Manufacturing Technology, 52 (2011) 929-935.

[23] W. Pan: The Machining of Titanium Alloys with Polycrystalline Diamond Tools, Ph.D. Thesis, 2014, 1-85.

\section{(c) (i) Creative Commons License}

This work is licensed under a Creative Commons Attribution 4.0 International License. 